\title{
REDES DIGITAIS: UM LOCAL DE PRODUÇÃO DE VERDADES NO CONTEMPORÂNEO?
}

\author{
REDES DIGITALES: ¿UN LOCAL DE PRODUCCIÓN DE VERDADES EN \\ EL CONTEMPORÁNEO? \\ DIGITAL NETWORKS: A PLACE OF TRUTH PRODUCTION IN THE \\ CONTEMPORARY?
}

http://dx.doi.org/10.1590/1807-03102016v28n3p412

Camila Mozzini

Universidade do Estado do Rio de Janeiro, Rio de Janeiro/RJ, Brasil e Universidad Politécnica de Valencia,

Valencia, España

Inês Hennigen

Universidade Federal do Rio Grande do Sul, Porto Alegre/RS, Brasil

\begin{abstract}
RESUMO
O presente artigo busca debruçar-se sobre o modo como as redes digitais vêm, atreladas a tantos sonhos e expectativas, diluindo-se discursivamente no tecido social a ponto de se constituírem enquanto um possível local de veridicção no contemporâneo. Para tal, uma série de incitamentos publicitários à conexão digital será tomada como campo de investigação empírica. O objetivo desta empreitada é problematizar certa concepção de rede que, ao contrário de teoricamente compor uma zona horizontal, abre-se à materialidade como uma instância atravessada por relações de poder e, portanto, produtora de desnivelamentos e conflitos.
\end{abstract}

Palavras-chave: redes digitais; relações de poder; mercado; neoliberalismo.

\section{RESUMEN}

El presente artículo discute el modo como las redes digitales vienen, atrailladas a tantos sueños y expectativas, se diluyendo discursivamente en el tejido social al punto de se constituyeren en cuanto un posible local de veridicción en el contemporáneo. Para tal, una serie de incitamientos publicitarios a la conexión digital será tomada como campo de investigación empírica. El objetivo de este proyecto es problematizar una cierta concepción de red que, al contrario de teóricamente constituir una zona horizontal, abre-se a la materialidad como una instancia atravesada por relaciones de poder e, por lo tanto, productora de desnivelamientos y conflictos.

Palabras clave: redes digitales; relaciones de poder; mercado; neoliberalismo.

\begin{abstract}
This article aims to understand how the digital networks, tied to so many dreams and expectations, have been diluting themselves discursively in the social fabric to the point of constituting themselves as a possible place of veridiction in the contemporary. To this end, a number of advertising incitements to digital connection will be taken as a empirical field of research. The goal of this endeavor is to discuss a certain conception of network that, instead of constituting a theoretically horizontal zone, opens itself to materiality as an instance traversed by power relationships and, thus, as a producer of unevenness and conflicts.
\end{abstract}

Keywords: digital networks; power relationships; market; neoliberalism. 


\section{Introdução}

Presenciamos hoje uma proliferação da palavra "rede" em diversos campos do viver: na psicologia, elas estão presentes em estudos sobre cognição, aprendizado e invenção; nos planos infraestruturais de centros urbanos, existem as redes de esgoto, redes viárias, aeroviárias e fluviais; nos mais recentes estudos neurocientíficos, têm-se as redes neurais; na biologia, há o estudo das redes bióticas; na informática, os cálculos em redes e as redes de computadores; no ciberespaço, as redes sociais e as guerras em rede. Até no mar encontram-se as redes de pesca e, entre as paredes, as redes de descanso. Frente a um cenário em que cada vez mais o viver é produzido através desta lógica reticular de relações, como podemos pensar as redes digitais no contemporâneo?

O presente artigo, resultado dos estudos elaborados em uma dissertação de mestrado que se debruçou sobre as condições de possibilidade da conexão digital se constituir como um universal a partir da publicidade, busca tensionar certo entendimento, que quer ser corrente, de que as redes digitais conectariam a "tudo" e a "todos" de forma isonômica e democrática. No âmbito dessa pesquisa, uma série de incitamentos publicitários à conexão digital foi tomada como campo de investigação empírica e foco de problematização de tal concepção de rede que vem se naturalizando no tecido social a partir do discurso publicitário. Foram analisadas seis publicidades em vídeo: Claro 3GMax ${ }^{1}$, Vivo Recomeço com a Internet ${ }^{2}$, Vivo - A vida com Internet ${ }^{3}$, Vivo - Vida Social com a maior cobertura $3 \mathrm{G}^{4}$, Vivo - Relacionamento sempre conectado ${ }^{5}$, Net - No dia em que eu virei mais $\mathrm{Net}^{6}$, e três embalagens dos produtos Club Social ${ }^{7}$, Halls ${ }^{8}$ e Trident ${ }^{9}$. Os referidos materiais foram coletados no momento em que encontraram corpo, pensamento e sentidos, causando extremo incômodo e vertigem na medida em que torceram o pensar frente à naturalidade com que propunham certa concepção de rede. Na sequência, a fim de apresentar e subsidiar discussões que as análises propiciaram, serão trazidas descrições de situações (cenas) e/ou excertos de enunciações presentes nessas peças publicitárias (com sua identificação entre parênteses).

Ao contrário de uma instância idílica que anularia as desigualdades intrínsecas ao atual modelo neoliberal, as redes são aqui concebidas como esferas atravessadas por relações de poder e, portanto, por forças exercidas a partir de "inúmeros pontos e em meio a relações desiguais e móveis" (Foucault, 2010, p. 104). Em sua incessante busca por visibilizar a artificialidade de verdades tidas como naturais, o pensamento de Michel Foucault consistirá, aqui, num importante inspirador para tal intento na medida em que possibilita compor outros olhares com relação ao devir histórico e às tessituras que hoje entremeiam redes e mercado.

Assim, este escrito busca, em um primeiro instante, confrontar a materialidade das redes digitais ao compósito de discursos publicitários que idealmente propõe a ideia de rede como atrelada aos imaginários de igualdade e horizontalidade dos nós interligados. Este primeiro movimento cria as condições necessárias para um segundo momento de tensionamento, no qual a noção de mercado em suas vertentes clássica, ordoliberal e anarcoliberal, trabalhadas por Foucault (2008) ao longo da obra Nascimento da Biopolítica, é tomada como forma de problematização das redes digitais enquanto instâncias de produção de verdade na contemporaneidade.

\section{Figura 1. Embalagens de produtos analisadas}

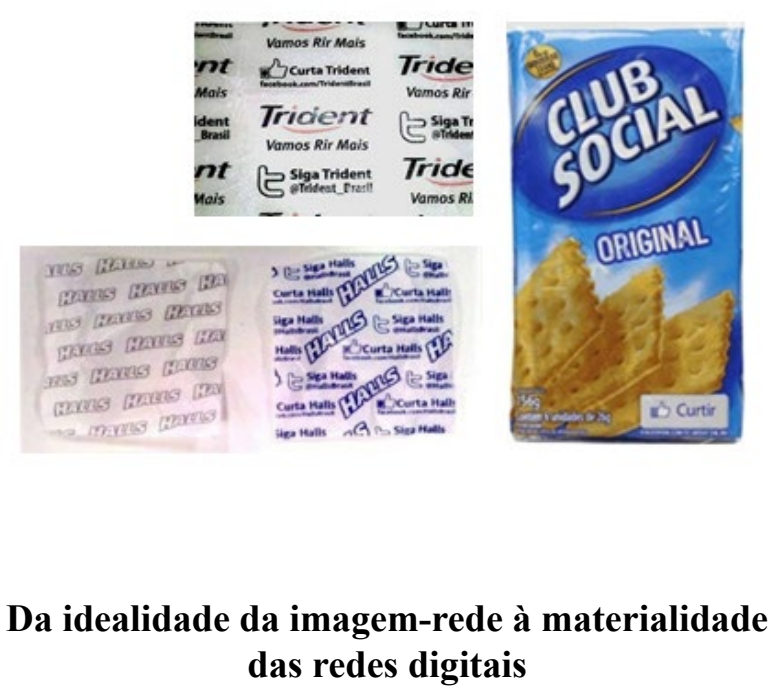

Não é de hoje que emergem as redes, senão o contrário, a noção de rede é bastante antiga e remonta a inúmeras construções históricas. No contexto ocidental, Musso (2010) assinala três movimentos principais: um primeiro seria a ideia de rede como um objeto externo ao corpo, exemplificado através da noção francesa de réseau enquanto redes de pesca, caça e tecidos e malhas que envolvem o corpo. O momento em que as redes adentram tanto as estruturas e tecidos do corpo quanto aparecem em formas da natureza como cristais e minerais traz um segundo movimento. Já o terceiro seria a grande ruptura que faz advir a noção de rede na passagem do século XVIII ao XIX, quando esta sai do corpo e das formas da natureza e se apresenta como algo que pode ser construído artificialmente em 
relação ao espaço. O processo de exteriorização das redes como artefatos técnicos se intensifica ainda mais conforme a internet ascende, se expande para além do restrito âmbito militar e se articula enquanto plataforma organizacional que atravessa o modelo capitalista. Desde então, a noção de rede materializa novos cenários e contornos: hoje é possível pensarmos na existência de uma rede mundial de computadores que interliga, espaço-temporalmente, por meio de cabos, fibras ópticas, satélites e ondas eletromagnéticas, não só usuários de redes sociais, mas também de sistemas financeiros, plataformas de atualizações de dados, centros de pesquisa em marketing, sistemas públicos e privados de administração, redes de serviços educacionais, sistemas de mídia e informação, serviços de pesquisa e buscas, dentre tantas outras possibilidades.

A peculiaridade que estabelece a ligação entre todas essas instâncias de ação parte da especificidade do que foi, a partir das análises realizadas, denominado como "imagem-rede". Diferente da concretude que vem delineando os contornos das redes digitais, a "imagem-rede", nesse âmbito, produz e abarca imaginários e ideais de convivência em um só mundo - visto que se propala que todos os pontos passariam a estar "igualmente" interligados pelo (simples) fato de serem possíveis através da conexão digital. No dizer da publicidade, é ela que permite que um jovem 'participe', de sua cama, da festa que não pode ir por estar com o pé quebrado (Claro $3 \mathrm{G}$ ); é ela que possibilita que se encontre a tão sonhada alma gêmea em recantos como uma ilha deserta, uma tribo indígena ou mesmo em uma caverna (Vivo 3); é ela que não dá mais desculpas para que amigos que estão distantes, seja em locais como um isolado pantanal cheio de jacarés ou em uma "terra distante" povoada de dragões, fiquem sem contato (Vivo 2); é ela que faz reencontrar antigos amores após o término de um casamento (Vivo 1); é ela que permite uma viagem aos quatro cantos do universo sideral (NET2); é ela que possibilita "fazer negócios com a rapidez que você precisa" (Claro3G).

Mas o que seria essa imagem-rede? Quais seriam as suas especificidades e as construções teóricas que a ancoram? Ao pensarmos em uma rede, provavelmente seremos tomados pela imagem de um emaranhado de linhas nas mais variadas curvaturas, todas interligadas por nós que não têm uma estrutura centralizada, mas que se distribuem em um conjunto disforme. Desse modo, a especificidade estrutural da imagem-rede enquanto um complexo de elementos que não se organiza a partir de uma hierarquia verticalizada abre espaço para uma série de imaginários. Há teóricos que propõem que estamos "interligando todos os centros de conhecimento do planeta e costurando uma única rede global" (Friedman, 2005, p. 17). Autor de $O$ mundo é plano - uma breve história do século XXI, Friedman propõe que a Terra teria deixado de ser redonda, como postulou Cristóvão Colombo, para se achatar com o advento das inovações tecnológicas e das reconfigurações trabalhistas como os processos de terceirização. Outros asseguram que, com as redes do ciberespaço, estaremos desbancando qualquer forma de autoridade, referência, dogma ou certeza na medida em que "estamos todos pensando na mesma rede" (Lévy, 2004, p. 13). Considerando a internet como um espaço onde tudo é possível e do qual nada é excluído, Lévy (2004) profetiza que é a rede que "vai nos fazer descobrir a verdadeira hierarquia do bem: uma hierarquia complexa, hipertextual, emaranhada, viva, móvel, abundante, turbilhante como a biosfera" (p. 12). É esta ausência de centralização, junto à possibilidade de conexões múltiplas e simultâneas, que faria das redes digitais "a nossa forma do infinito" (Vaz, 2010, p. 201) e do tão desejado ilimitado.

Em meio a tantos sonhos e promessas, Paulo Vaz (2010) lista cinco esperanças suscitadas com a emergência das redes digitais em dias em que se projeta a internet como meio de comunicação hegemônico. A primeira seria a de democratização: viveríamos o fim da intermediação dos políticos e do sistema representativo, uma vez que a cidadania seria conquistada pela participação de todos, eliminando a necessidade de qualquer forma de mediação. A segunda seria a possibilidade de a troca substituir a ordenação oferta/produção do mercado através da web. A terceira diz respeito à educação: "A rede seria, ao mesmo tempo, uma imensa biblioteca acessível a todos e uma universidade que tem como professores e alunos a humanidade" (p. 205). A quarta esperança suscitada pela rede seria a de uma nova sociabilidade, pois, "por estarmos próximos de qualquer um, poderíamos encontrar quem desejamos na rede" ( $p$. 205), pondo um fim à temida companhia da solidão. Por fim, a última tange à identidade: é possível ser o que se é, ser múltiplo e ainda tornar nosso ser mais tolerante através da experimentação do território existencial do outro.

Desse modo, seria a imagem-rede tão horizontal quanto a materialidade das redes digitais? Todos os pontossetornariamigualmente acessíveis nas redesque falam a língua dos bits? A definição de rede, segundo Musso (2010), traz um aspecto interessante para a discussão na medida em que assinala uma rede como "uma estrutura de interconexão instável, composta de elementos em interação, e cuja variabilidade obedece a alguma regra de funcionamento" (p. 31). O 
que salta aos olhos é a utilização da palavra "regra" para conceituar algo que, em uma primeira instância, parece romper com qualquer forma de ordenamento. "Supõe-se que a variabilidade da estrutura em rede respeita uma norma" (p. 32), ou seja, para que possam existir, as redes digitais possuem todo um conjunto de regramentos técnicos que possibilitam sua estrutura organizacional. E esta não horizontalidade pode ser levada à radicalidade quando se entra em um território denominado "deep web": sites que não são indexados por mecanismos de busca ou que só podem ser encontrados através de sistemas de encriptação avançados. Em contraste com a chamada "surface web", isto é, a web usualmente utilizada, a deep web "é a categoria que mais cresce em novas informações na internet. O valor do conteúdo da deep web é incomensurável, buscadores na internet estão procurando por apenas $0,03 \%$ [do total das] páginas web disponível" [tradução das autoras], afirma o pesquisador Michael Bergman em matéria para a versão virtual do jornal britânico The Guardian. Não há como mensurar, mas calcula-se que a deep web seja pelo menos quinhentas vezes maior que a surface web e abrigue todo tipo de informações, inclusive as ilegais, tais como pornografia infantil, redes de contatos criminosos e distribuição de vírus de computadores.

Nesse sentido, a questão da horizontalidade das redes, que em um primeiro instante constituiria uma instância de anulação de estratégias de mediação, sejam estas políticas ou midiáticas, produz, ao contrário, uma multiplicação de filtros e intermediários que não estão visíveis ao usuário comum. Ou até mesmo de protocolos que escapam aos filtros de sites de buscas - como no caso da deep web. Assim, mediante o emprego de robôs e metarrobôs, a automediação dos conteúdos na "surface web", ainda que tensionem as formas clássicas de mediação, desnaturam "o projeto de uma relação direta, límpida com peças de informações" (Weissberg, 2010, p. 125), produzindo outras instâncias de centralização das práticas digitais. Para Vaz (2010), existem duas formas de mensurar a formação destes espaços de centralização: a primeira seria a da intermediação, na qual "um nó é tão mais central quanto mais é necessário para que dois nós quaisquer se conectem” (p. 206), e a segunda medida seria a acessibilidade, ou seja, quanto maior for a quantidade de nós para se chegar à informação desejada, menor é a acessibilidade e maior é o excesso de informação. Assim, ao invés de desaparecer, a função mediadora se renova em meio aos territórios virtuais através do uso de "instrumentos exteriores - transcendentes?" (Weissberg, 2010, p. 125) que se colocam "entre o internauta e a imensa maré informacional em permanente cheia, a fim de assegurar a pesquisa e a avaliação das informações obtidas" (p. 125). Se até mesmo as linhas de força que mobilizam as relações de poder procedem por meio de "redistribuições, alinhamentos, homogeneizações, arranjos de série" (Foucault, 2010, p. 105), por que estariam as redes digitais imunes às desigualdades que permeiam o atual modelo neoliberal?

\section{Interfaces e imbricamentos entre redes digitais e mercado}

O livro A era do acesso, de Jeremy Rifkin (2001), que traz no subtítulo "Quando os mercados dão lugar às redes", aparece como um caminho interessante para pensar a atual relação entre mercado e redes digitais. De acordo com o autor, a noção de rede está "se tornando cada vez mais importante e começando a redefinir nossa dinâmica social de uma forma tão poderosa quanto à redefinição de propriedade e de mercados às vésperas da era moderna" (Rifkin, 2001, p. 12). É nesta direção que a noção clássica de propriedade cada vez mais perde relevância e se abre espaço à ideia de acesso a experiências comerciais compartilhadas através de uma economia em rede. Mas, primeiramente, que mercado é esse que Rifkin (2001) afirma dar espaço às redes? Para o autor, a palavra "mercado", do inglês market, emergiu no século XII como o espaço físico em que vendedores e compradores realizavam a troca de bens e de gado. Ao fim do século XVII, entretanto, o termo se desligou de referências a territórios geográficos para designar "o processo abstrato de vender coisas" (Rifkin, 2001, p. 3). Desde então, o mundo teria ficado "tão ligado ao processo de vender e comprar coisas no mercado que não podemos imaginar qualquer outra maneira de estruturar os negócios humanos" (p. 3). Através de embates travados historicamente, a naturalização das práticas de mercado nos processos cotidianos o tornou "uma força avassaladora em nossas vidas" (p. 3), chegando ao ponto de afetar humores e sabores: "Se os mercados estão saudáveis, sentimo-nos animados. Se enfraquecem, entramos em desespero. O mercado é nosso guia e conselheiro e, às vezes, a maldição de nossa existência" (p. 3).

Atrelando a noção de mercado à sua constituição liberal e neoliberal, Foucault (2008) faz um mapeamento de três configurações históricas de mercado. A primeira é a concepção liberal clássica, na qual o mercado seria uma instância que naturalmente regularia os processos econômicos. Basta deixar o mercado agir pelas suas próprias leis, sem intervir nele - tal como propõe a máxima do laissez-faire - 
que uma mão invisível faria com que os preços e a balança comercial se regulassem. O mercado constitui, então, um lugar e um mecanismo de formação de verdade a partir da mínima intervenção estatal. Desde o século XVIII o mercado emerge como um local de veridicção, isto é, "como revelador de algo que é como uma verdade" (p. 44), posto que sua lógica obedecia não mais a ações mal intencionadas de sujeitos, mas sim a mecanismos naturais que espontaneamente se autorregulavam e equilibravam os processos de trocas.

Já a segunda configuração de mercado remonta ao contexto alemão pós-Segunda Guerra Mundial. Frente aos horrores do nazismo, pairava no ar uma desconfiança geral em relação ao renascimento de um possível Estado forte na Alemanha. É nesse cenário que ganha força uma corrente de pensamento denominada ordoliberal a qual, portadora de uma forte crítica às políticas keynesianas que reconstruíam a Alemanha, postulava que qualquer modelo estatal de economia planificada necessariamente levaria ao totalitarismo. Assim, a questão na Alemanha era bastante delicada: como restabelecer um Estado sem que se corresse o risco de recriar um Estado nazista? Como enfrentar esta memória histórica e construir um modelo estatal imune a tal ameaça? A resposta alemã ordoliberal é clara: a gênese do Estado tem de se dar pela economia e é através dela que o Estado "recupera sua lei jurídica e recupera seu fundamento real" (Foucault, 2008, p. 116). O que está em questão no neoliberalismo alemãoé partir de uma liberdade econômica que vai tanto limitar a presença do Estado quanto permitir a sua existência. Para isso, uma série de deslocamentos em relação à concepção liberal clássica é realizada: ao invés do princípio da troca, coloca-se em jogo o princípio da concorrência; ao invés da busca pela igualdade, incitase ao desigual. A intervenção estatal jamais se dá no mercado, mas nas condições de mercado, o que implica na construção de uma moldura jurídica e institucional que tem a população como objeto e alvo de gestão. Para tal, há uma multiplicação da lógica empresarial no interior do corpo social, fazendo do mercado e da concorrência um poder enformador da sociedade. É somente a partir desta multiplicação do modelo empresa que o mercado pode emergir, então, como um regulador político-econômico que não é mais fruto de uma ordem natural nem espontânea.

A terceira e última configuração do mercado seria a proposta pelo neoliberalismo americano ou anarcoliberalismo. De modo similar ao contexto alemão, os Estados Unidos também estavam em meio aos efeitos do período pós-Segunda Guerra Mundial, nos quais despontavam as políticas keynesianas, o crescimento da administração federal através de programas econômicos e sociais e o crescimento das críticas em relação ao dirigismo econômico por parte do Estado. Apesar de apresentar similaridades quanto ao ordoliberalismo, a especificidade do cenário estadunidense está no fato de que a própria fundação do país se deu com base em reivindicações liberais. Assim, mais que uma opção econômica e política, o anarcoliberalismo "é toda uma maneira de ser e de pensar. É um tipo de relação entre governantes e governados, muito mais que uma técnica dos governantes em relação aos governados" (Foucault, 2008 , p. 301). Cristaliza-se uma radicalização do modelo empresa enquanto organizadora social a partir da expansão dos processos de mercado para territórios considerados como não econômicos: o percurso dos indivíduos em vida e os investimentos que receberam e fizeram em formação geram, então, um capital humano a ser produzido, acumulado e remunerado de acordo com as competências de cada um. A desigualdade e a concorrência alicerçam as bases biopolíticas de indivíduos que gerenciam a si mesmos como se empresas fossem. Cabe a cada um saber dos riscos que se pode tomar e cada um deve se responsabilizar pela sua própria segurança. Uma sociedade de autônomos. $\mathrm{O}$ desemprego e as diferenças de renda não seriam mais problemas a serem solucionados, mas sim elementos necessários para instaurar a desigualdade como condição estrutural da sociedade e dinamizar o jogo concorrencial.

Temos então um mercado autorregulado que se organiza por suas próprias leis naturais, outro que não se regula naturalmente, mas alicerçado em uma moldura institucional empreendedora que possibilita a atuação do mercado como regulador político-econômico, e um último que encarna tal moldura no corpo, inserindo a lógica da empresa no percurso em vida do trabalhador - e do sujeito em geral - com base na noção de capital humano. Claro que essas modulações de mercado não são instâncias separadas e incomunicáveis, entretanto, apesar de se (re)comporem conjuntamente, cada concepção de mercado tem a sua especificidade na medida em que se localizam em tempo e espaços diversos. A questão que fica é: como poderíamos pensar os formatos de mercado liberal, ordoliberal e anarcoliberal em relação a uma economia que cada vez mais atravessa as redes digitais e nos provoca a partir de uma nova governamentalidade? Para visibilizar a mútua implicação que mercados e redes digitais hoje vêm engendrando, nada melhor que trazer o exemplo das redes sociais e o modo como os incitamentos publicitários à conexão digital as retratam.

Mas e por que trazer o exemplo das redes sociais? $\mathrm{O}$ que as redes sociais têm a ver com a intersecção 
entre redes digitais e mercado? Primeiramente, não podemos perder de vista a importância das redes sociais naquelas três aparentemente despretensiosas embalagens de Halls, Trident e Club Social: além do emblema da marca, os outros dois elementos impressos remetem tanto ao Facebook quanto ao Twitter. Tendo em vista que a embalagem é uma peça publicitária que busca engendrar na identidade visual ao produto, não é irrelevante que as marcas estejam diretamente atreladas às duas redes sociais em questão. Segundo, porque cinco incitamentos publicitários em vídeo (Claro3G, Vivo 1, Vivo 2, Vivo 3, Vivo 4) trazem explicitamente a questão das redes sociais em suas imagens e textos. Dessa maneira, a forma como as demandas econômicas de produção e oferta e circulação hoje se encarnam na publicidade e perpassam a lógica das redes por meio das novas plataformas de comunicação pode nos dar algumas pistas sobre os modos como redes digitais e mercados se entrelaçam e produzem territórios de sentido.

Primeira questão a tensionarmos: tal qual a noção de mercado ordoliberal, as redes digitais teriam a necessidade de uma moldura institucional para que possam produzir seus efeitos? Estaríamos presenciando a constituição de uma política de intervenção nas 'condições de rede', e não nas redes em si? Seriam as redes ingovernáveis? Esse tensionamento nos direciona ao fato de que, segundo o incitamento publicitário Vivo 3, a "vida fica melhor quando a internet está sempre com você, e melhor ainda quando você pode ficar conectado $24 \mathrm{~h}$ por dia com seus amigos nos quatro cantos do país". É interessante ressaltar que este comercial fala especificamente das redes sociais, de seus usos e de como elas possibilitam uma nova sociabilidade. Mas o que implica a possibilidade de se estar conectado a amigos durante todas as horas do dia em qualquer lugar? Primeiramente, implicaria uma série de investimentos em estrutura física e organizacional por parte das operadoras de telecomunicação para que as redes digitais tenham tal alcance: fibras ópticas, torres de sinal, satélites e todos os tipos de cabos. Todavia, em julho de 2012 diversas operadoras brasileiras, dentre elas a Oi, Tim e Claro, foram temporariamente proibidas pela Agência Nacional de Telecomunicações (Anatel) de vender chips para celulares enquanto não investissem na melhoria de seus serviços de conexão digital. Em entrevista à Revista Veja, o presidente da Anatel, João Batista de Rezende, afirmou: "O que estamos dizendo às empresas é: se quiserem oferecer serviços de internet e de voz ilimitados, ou dar descontos e bônus agressivos, terão que investir na rede e na qualidade para dar contrapartida ao que oferecem"(“As operadoras", 2012). Ou seja: as redes digitais não possibilitam o propagado "ilimitado" sem que primeiramente exista uma moldura jurídica e infraestrutural de investimentos que habilite o usuário a ficar 24 horas com seus amigos e em todos os lugares através das redes sociais.

Em meio a instável e ainda inexistente moldura, criam-se intervenções que visam viabilizá-la: em tempos de Copa do Mundo e Olimpíadas no Brasil, criam-se políticas públicas de incentivo à produção tecnológica e inclusão digital. Mas e nas redes, há intervenção? Em países como China, Coreia do Norte, Rússia e Arábia Saudita, por exemplo, a prática da censura, a restrição ao acesso a certos sites e a impossibilidade de busca por determinadas palavraschave fazem parte de uma política estatal de controle das redes. Contudo, nos ditos países democráticos, as estratégias de regulação das redes digitais também estão presentes, ainda que de forma diferente. "No Reino Unido, o governo anunciou planos para monitorar o uso de e-mail e das redes sociais pelos cidadãos" - afirma reportagem da revista Carta Capital ("A Internet ameaçada", 2012). Nos Estados Unidos, recentemente os projetos de lei Stop Online Piract Act (SOPA) e Protect IP. Act (PIPA), que restringem o compartilhamento, nas redes, de conteúdos que possam infringir direitos autorais de produções hollywoodianas e de grandes estúdios, tiveram suas votações adiadas por tempo indeterminado após uma longa onda de protestos tanto de empresas quanto de ativistas nas redes digitais e também nas ruas.

No Brasil, está circulando desde 1999 o projeto de Lei no 84/1999, popularmente conhecido como "Lei Azeredo" em razão do sobrenome de seu proponente, o deputado Eduardo Azeredo (PSDB - MG), e carinhosamente apelidado como "AI-5 digital" por ativistas que entendem a norma como uma ameaça à liberdade e aos direitos dos usuários na web. Demi Getschko, presidente do Núcleo de Informação e Coordenação do Ponto BR (NIC.br) - entidade civil, sem fins lucrativos, que desde dezembro de 2005 implementa as decisões e projetos do Comitê Gestor da Internet no Brasil - propõe que "temos de aprovar um marco civil, que sacramente os direitos e conceitos da rede" ("Na internet, o indivíduo fica nu", 2012). Tal regulamentação passou por um amplo processo de consulta pública e teria por objetivo proteger os dados dos usuários de serem utilizados de forma nociva por empresas prestadoras de serviço na rede. Em entrevista à Revista Caros amigos ("Internet livre", 2013), Sérgio Amadeu, pesquisador e militante do software livre que integra o Comitê Gestor da Internet no Brasil, salienta que a rede "é técnica, mas não é somente técnica, ela é principalmente política e econômica. Imagine se uma operadora resolve, por motivos de 
suas convicções culturais ou políticas, começar a filtrar determinado tipo de tráfego, de informação".

Assim, mesmo ainda não havendo uma moldura jurídica e institucional, criam-se as condições para a emergência de uma sociedade que instaura, cada vez mais, nas redes sua forma organizacional: redes de conhecimentos, de competências, de comércio, de sentidos, de contatos, de amigos, de inimigos são compostas a partir do acoplamento entre relações de troca e relações sociais. Não por acaso, desde a década de 1990, que o sociólogo espanhol Manuel Castells vem afirmando que vivemos em uma "sociedade em rede" (Castells, 2010). Mas residem aí algumas nuances: em um primeiro momento, as estratégias de intervenção e regulação ficariam restritas à constituição desta moldura, ou seja, às condições da rede. Porém - e esta é uma das contradições mais frequentes das políticas econômicas neoliberais com relação ao mercado -, ainda que o âmbito de intervenções se proponha idealmente a não 'meter a mão' nas redes digitais em si, não é o que vem acontecendo hoje, tendo em vista que uma das maiores frentes de ações estatais e privadas busca a todo custo e contra todas as correntes uma regulamentação dos usos e desusos das redes. Se nos incitamentos publicitários à conexão digital analisados as redes sociais são retratadas como um território que permite postar, twittar, curtir, comentar e compartilhar tudo, a todo momento e de qualquer lugar, se através delas os usuários podem usufruir das liberdades da rede, é importante pautar que este terreno de liberdade é bastante movediço, desnivelado e em constante embate político.

É a partir deste ponto que podemos lançar uma segunda questão de tensionamento: tal qual a concepção anarcoliberal de mercado proposta por Foucault (2008), as redes digitais seriam uma instância de expansão da economia a territórios considerados como não econômicos? Estariam as redes digitais constituindo um espaço de aquisição de capital humano? De que modo a estrutura organizacional das redes digitais possibilita a radicalização da noção de indivíduo enquanto empresário de si? Tomando novamente as redes sociais como exemplo, é interessante notar que a ideia de sujeito como empresário de si, nos incitamentos publicitários à conexão digital, atrela esta ferramenta ao ato de fazer "milhares de amigos" e fazê-los com a velocidade "de um cometa". Assim, enquanto NET 2 traz a personagem de Suzana batendo e cumprimentando dezenas de mãos em segundos, o incitamento publicitário Vivo 3 propõe que devemos "alimentar nossas amizades" onde estivermos, visto que o "amigo é um ser carente e precisa de atenção. Seja o primeiro a curtir uma foto no Facebook, dar o retwitt numa pérola ou comentar um link". Não por acaso, foi também através das redes sociais que a personagem de Bia pôde, em Vivo 1, reencontrar o "ex-chefe, amiga da faculdade e até o... Paulinho!". De casada e isolada em uma bolha social, após a separação "tudo mudou" quando ela "entrou na sua primeira internet", isto é, quando conectou seu computador ao modem móvel dessa empresa. E não importa o aparato eletrônico a ser utilizado: pode ser no celular, computador, notebook ou tablet, o importante para a Claro $3 \mathrm{G}$ é estar conectado para "adicionar" amigos como o personagem de Guto, dar $c h e c k-i n^{10}$ nos lugares onde se está, fazer downloads e mandar e-mails em máxima velocidade.

Dentre tantas imagens sobre redes sociais, processa-se uma regularidade, uma repetição discursiva que chama especial atenção nos incitamentos publicitários em questão: não há redes sociais sem relacioná-las àadição de amigos. Aoperaçãomatemática da soma, aprendida nas primeiras incursões escolares como um elemento básico de conhecimento, agora emerge enquanto articulador fundante das relações que se processam através da estrutura organizacional das redes sociais. Adicionar um amigo hoje parece uma prática cada vez mais comum: não raro, quando se conhece alguém, já se pergunta pelo nome da pessoa para buscá-la no Facebook e "adicioná-la". A partir de tal lógica, acumulamos e colocamos em circulação não só bens materiais frutos dos processos de produção e oferta, mas principalmente seres humanos, relações entre seres humanos, entre pessoas, contatos, sejam estes profissionais, familiares, de amizade ou até de desconhecidos que cruzam nossos corpos físicos e virtuais ao longo do percurso da vida.

De acordo com Recuero e Zago (2012), os valores gerados nos sites de rede social são correntemente designados como capital social, uma vez que esse, como qualquer outra forma de capital, "é produto de investimento dos indivíduos em suas redes e da construção de valor nesses espaços" (p. 22). Isto porque, conforme as autoras, "existe um alto custo para a obtenção de informações numa rede social, que não apenas exige atenção, mas igualmente envolvimento do ator na busca por fontes que sejam relevantes para a área de interesse" (Recuero \& Zago, 2012, p. 24). Não por acaso, o sujeito econômico neoliberal é um sujeito que posiciona em primeiro plano a satisfação de seus interesses e anseios. É nesta perspectiva que as redes sociais materializam uma expansão da economia a territórios em princípio não econômicos, pois a quantidade de amigos, as redes de contatos e as mensagens postadas constituem elementos de produção de capital humano, ou seja, implicam em 
ativos de visibilidade, recurso deveras disputado nas prateleiras do consumo subjetivo de modos de vida no contemporâneo. Se, como propõe Castells (2010), estamos em uma "sociedade em rede", é preciso que invertamos a ordem desta expressão para que observemos a forma como as "redes sociais" vêm nos afetando e engendrando uma interessante relação entre redes e sociedade que procura estabelecer na ideia de visibilidade um componente fundamental das relações sociais.

Mas há um último ponto de tensionamento na relação entre redes digitais e mercado que ainda está intacto e que não aleatoriamente foi deixado para o final: seriam as redes uma instância que se autorregula naturalmente, tal qual a concepção liberal clássica de mercado? Estariam as redes digitais constituindo um lugar de veridicção, revelando algo que é como uma verdade? Quando falamos em verdade, é preciso antes aclarar que os jogos de verdade devem ser entendidos, segundo Nardi e Silva (2009), como o conjunto de regramentos que produzem a experiência do verdadeiro e do falso, ou seja, como um âmbito de práticas imersas em mecanismos onde o poder se faz presente. É ao longo dos processos de legitimação social dos jogos de verdade que são produzidos os chamados regimes de verdade, instância caracterizada por sua dupla função de dominação e de identificação, possibilitando a abertura de espaços que tanto reiteram as formas de dominação normalizadas quanto de brechas que viabilizam a resistência às verdades hegemonicamente constituídas (Nardi \& Silva, 2009). Para Foucault (2011, p.12), "a verdade não existe fora do poder ou sem poder". Assim, ao contrário da busca pelo "conjunto das coisas verdadeiras a descobrir ou a fazer aceitar" (p. 13), a questão da verdade, sob tal perspectiva, insere-se em um território político no qual o binômio verdade/ poder se torna um elo vital para a problematização das atuais políticas de verdade.

É fato que hoje cada vez mais vivenciamos os mecanismos de mercado atravessados pelas redes digitais que o dinamizam. Por meio delas, as trocas que antes estavam restritas às distribuições geográficas prescindem de sua presentificação local. Não que não existam mais mercados alheios à atual lógica reticular - obviamente, ainda existem espaços em que as trocas sequer são pensadas em termos monetários -, porém, quando pensamos na realidade dos centros urbanos e nas contemporâneas políticas econômicas, taxas de juros diversas e bolsas de valores interligadas mundo afora impactam diretamente nas decisões estatais e privadas em relação ao mercado financeiro. As redes digitais são hoje um elemento estrutural que impulsiona os processos concorrenciais através de um aumento cada vez mais vertiginoso da velocidade dos intercâmbios financeiros. Não é à toa que a expressão "economia em rede" (Castells, 2010; Rifkin, 2001 ) emerge como possível ao pensamento contemporâneo: condições de possibilidade bastante singulares mobilizam a atual composição histórica e posicionam as redes enquanto um elemento ontológico organizador e produtor de efeitos de real.

\section{Redes digitais e mercado: um novo laissez-faire?}

O incitamento publicitário à conexão digital Vivo 4 oferece uma interessante pista para pensarmos esta relação entre redes digitais e mercado: a imagem de um jovem sentado ao computador buscando pela expressão "alma gêmea" no "Gooble" - homônimo do site de buscas Google. Ao invés de direcionar seus anseios por respostas a questões existenciais através de orações, o rapaz não precisa mais sofrer os percalços do acaso, já que basta acessar o "Gooble" para facilmente encontrar a verdade sobre a tão desejada alma gêmea, esteja ela em "uma ilha deserta, dentro de uma caverna ou numa oca". As redes simplesmente sabem. E elas não só têm as respostas como as localizam nos lugares mais improváveis. Talvez, a razão maior "da aceitação surpreendentemente rápida da internet" (Vaz, 2010, p. 202) esteja na "promessa de dotar o indivíduo com a ubiquidade. Na rede, estamos em lugar nenhum e em todos os lugares, podendo trocar informações ou interagir com quem ou o que se quiser no momento em que desejamos" (p. 202).

Seriam as redes, então, reguladas por mãos invisíveis, espontâneas, assim como o mercado proposto por Adam Smith? Para pensadores como Pierre Lévy, talvez sim. Isto porque, segundo o autor, quanto mais o mercado se desenvolve e "penetra nas profundezas da vida social, mais ele se libera, e mais parece que as ideias, as músicas, as imagens, as ferramentas, os serviços de todos os tipos são trazidos à existência por terem sido escolhidos" (Lévy, 2010, pp. 183-184). Partindo do pressuposto de que seríamos indivíduos suficientemente emancipados para realizar livremente nossas escolhas, a consciência humana, entendida por Lévy (2010) como a energia psíquica última, tornar-se-ia o elemento organizador do mercado no momento em que internaliza a lógica concorrencial. Atingiríamos, então, o ápice deste processo no momento em que "a economia se torna uma economia da atenção, isto é, da consciência" (Lévy, 2010, p. 184), e é neste ponto que "não há mais diferença entre economia e espiritualidade" (p. 184). Interligando três entidades bastante caras às Humanidades, mercado, 
redes digitais e consciência abrem espaço à via "da unificação, da liberação e da dilatação ilimitada" (Lévy, 2010, p. 188). Forma-se, assim, "uma espécie de templo da religião comunicacional mundial" (Musso, 2010 , p. 36) que conecta o presente e o futuro através da promessa de "paz e democracia pela circulação e pela conexão generalizadas" (p. 36).

Talvez estejamos voltando aos clássicos e caindo novamente na ingenuidade naturalista liberal, que acreditava que o mercado regulava os processos de trocas na medida em que espontaneamente se chegava a uma equivalência geral. De modo similar a um mercado autorregulável, "a democracia reticular põe cada um numa situação de passagem, 'conectando-o' a uma rede. O presente é passagem, transição, movimento. Não há mais necessidade de operar a mudança social, ela se faz permanentemente" (Musso, 2010, p. 37). A partir de uma concepção de tempo que se desenraiza de suas arenas de embates, a emergência das redes digitais por si só, sua mera e simples existência, seria então o veículo das mudanças e aspirações à igualdade tão presentes no imaginário humano. Nesta perspectiva, a rede se torna "o fim e o meio para pensar e realizar a transformação social, ou até mesmo as revoluções de nosso tempo" (p. 37). Encontramo-nos diante de um interessante paradoxo: ao mesmo tempo que as redes emergem como um repositório de desejos, esperanças e sonhos, a capacidade de realização de tais anseios fica estanque ao movimento das próprias redes, esvaziando politicamente o trabalho de si sobre si mesmo e sobre o outro tão necessário para que haja qualquer forma de transformação das subjetividades individuais e coletivas.

Desse modo, a rarefação enunciativa da palavra rede vem produzindo na contemporaneidade uma dispersão que implica em sua diluição no tecido social. Diluição esta que não só espalha a noção de rede como a naturaliza em diferentes áreas de saberes e formações discursivas. Problematizar se faz necessário. $O$ processo de exteriorização das redes no ocidente possibilitou ao pensamento que elas fossem construídas enquanto artefatos técnicos que não se restringem aos mecanismos biológicos da natureza e do corpo humano. A ideia de que formam um conjunto de elementos interligados inspirou muitos a produzirem um compósito conceitual, aqui denominamos como "imagem-rede", capaz de ligar pontos horizontalmente e em pé de igualdade entre seus nós. É nesta imagem que se depositaram os mais diferentes sonhos e esperanças de construção de um mundo menos hierárquico, limitado e/ou elitista. As redes encarnam uma espécie de utopia da liberdade que para muitos constitui a essência da raça humana.
No entanto, nem mesmo as redes digitais escapam às desigualdades provenientes dos jogos de força em constante tensionamento por meio de relações de poder e saber. Existem desníveis, barreiras linguísticas, visualizações que se diferenciam a partir de protocolos de uso da web, centralizações provenientes dos processos de mercado. Mesmo fazendo uma abertura que multidimensionaliza os discursos hegemônicos, ao invés de eliminar os intermediários que disseminam a informação, presenciamos uma multiplicação de outros filtros: intermediários automatizados e robotizados de seleção de dados. Não por acaso, as redes digitais hoje perpassam os processos de mercado e com ele ganham novos usos e territórios: regulam-se as condições das redes, interfere-se nas próprias redes, estas emergem enquanto espaço de constituição de capital humano e, por fim, parecem se colocar como um local de produção de verdade.

Contudo, é somente quando abstraímos e descolamos as redes digitais de sua infraestrutura material e de sua gênese histórica que chegamos ao atual estágio onde estas podem emergir, bem como a noção de mercado liberal, enquanto instâncias que revelam algo como uma verdade. Se, para Rifkin (2001), estamos partindo do mercado em direção às redes, mais do que passar de um ao outro, assistimos a uma recomposição do mercado através das redes e de uma transmutação das redes que perpassa as lógicas de mercado. Como bem pontua Musso (2010), as redes não estão imunes aos mecanismos econômicos: "Essa teologia dos evangelistas da rede vai de encontro à dos empresários que veem ali um 'mercado' para um comércio eletrônico ao mesmo tempo mundializado, personalizado e acessível a domicílio" (p. 35). Processa-se aí uma imbricação tão interdependente quanto o sangue que circula em nossas veias e possibilita a continuidade da vida, uma tessitura tão íntima que mínimas embalagens de Halls e Trident, além do invólucro de Club Social, estampam as relações entre estratégias mercadológicas e redes. E tamanho entrelaçamento não raro desperta estratégias de resistência que buscam justamente tensionar tanto as redes como os mercados mediante invasões hackers a sites como os do Federal Bureau of Investigation (FBI) e do Banco Mundial. Estamos em um território conflituoso e em constante disputa. Por isso, tornar as redes um local de veridicção implica em reificarmos um fluxo discursivo que se movimenta por meio de uma 'ingenuidade' que invisibiliza processos que estão materializados em nossas práticas. É necessário antes estarmos atentos - e a atenção hoje é um recurso cada vez mais raro frente a tantos estímulos - para que possamos costurar um olhar histórico sobre as linhas de força que vêm engendrando nas redes digitais 
um reduto privilegiado de produção de verdades no contemporâneo.

\section{Notas}

1 Vídeo disponível em http://www.youtube.com/ watch?v=Kd6V59XOYPo Acesso em 18 /02/2014, utilizaremos a abreviação Claro $3 \mathrm{G}$ neste artigo.

2 Vídeo disponível em http://www.youtube.com/ watch? $\mathrm{v}=\mathrm{JZNuCCa0OI4}$, Acesso em 18/02/2014, utilizaremos a abreviação Vivo 1 neste artigo.

3 Vídeo disponível em http://www.youtube.com/ watch? $v=$ GyL3ZqQeG5A. Acesso em 18/02/2014, utilizaremos a abreviação Vivo 2 neste artigo.

4 Vídeo disponível em http://www.youtube.com/watch?v=SXFHIIrShc. Acesso em 18/02/2014, utilizaremos a abreviação Vivo 3 neste artigo.

5 Vídeo disponível em http://www.youtube.com/watch?v= Nb2KCfzuaJA\&feature $=$ relmfu. Acesso em 18/02/2014, utilizaremos a abreviação Vivo4, neste artigo.

6 Vídeo disponível em http://vimeo.com/22464707. Acesso em 18/02/2014, utilizaremos a abreviação Net 2 , neste artigo.

7 Embalagem do produto Club Social que tem impresso em sua frente o sinal de positivo com a palavra "Curtir", composição que ficou popularmente conhecida através da rede social Facebook. Facebook.com/clubsocialbr é o local onde se pode demonstrar a afeição ao produto.

8 O papel que envolve a pastilha Halls tem impressos, além do emblema da marca, as frases "Siga Halls - @ HallsBrasil" com o "t" característico da rede social Twitter ao lado e "Curta Halls - facebook.com/HallsBrasil", também com o sinal de positivo que caracteriza a ferramenta curtir no Facebook.

9. Semelhante ao invólucro de Halls, a embalagem que envolve o chiclete Trident traz as passagens "Siga Trident - @ Trident_Brasil" com o "t" de Twitter e "Curta Trident facebook.com/TridentBrasil" com o curtir do Facebook.

10 Check-in é uma ferramenta utilizada geralmente em sites de redes sociais que possibilita que se compartilhe online a informação do local em que se está no momento.

\section{Referências}

A Internet ameaçada. (2012, 16 de abril). Carta Capital. Acesso em 12 de fevereiro, 2014, em http://www.cartacapital.com. br/tecnologia/a-internet-nunca-esteve-tao-ameacada-diz-cofundador-do-google

As operadoras se descuidaram. (2012, 16 de setembro). Veja. com. Acesso em 12 fevereiro, 2014, em http://veja.abril. com.br/noticia/economia/as-operadoras-se-descuidaramafirma-presidente-da-anatel

Castells, M. (2010). A sociedade em rede - A era da informação: economia, sociedade e cultura (R. V. Majer, Trad., $6^{\mathrm{a}}$ ed.) São Paulo: Paz e Terra.

Foucault, M. (2008). Nascimento da biopolítica (E. Brandão, Trad.). São Paulo: Martins Fontes.

Foucault, M. (2010). História da Sexualidade I: a vontade de saber (M. T. C. Albuquerque \& J. A. G. Albuquerque, Trads.). São Paulo: Graal.
Foucault, M. (2011). Microfísica do Poder (R. Machado, Trad.). São Paulo: Graal.

Friedman, T. L. (2005). O mundo é plano: uma breve história do século XXI (C. Serra \& S. Duarte, Trads.). Rio de Janeiro: Objetiva.

Internet livre. (2013, 24 de janeiro). Caros amigos. Acesso em 12 de fevereiro, 2014, em http://www.carosamigos.com. br/index.php/politica/1171-empresas-de-telefonia-barramvotacao-do-marco-civil-da-internet/

Lévy, P. (2004). Uma perspectiva vitalista sobre a cibercultura. In A. Lemos (Org.), Cibercultura - tecnologia e vida social na cultura contemporânea ( $2^{\mathrm{a}}$ ed., pp. 11-13). Porto Alegre: Sulina.

Lévy, P. (2010). O ciberespaço e a economia da atenção. In A. Parente (Org.), Tramas da rede: novas dimensões filosóficas, estéticas e políticas da comunicação (pp. 174-188). Porto Alegre: Sulina.

Musso, P. (2010). A filosofia da rede. In A. Parente (Org.), Tramas da rede: novas dimensões filosóficas, estéticas e políticas da comunicação (pp. 17-38). Porto Alegre: Sulina. $\mathrm{Na}$ internet, o indivíduo fica nu. (2012, 19 de janeiro). Carta capital. Acesso em 12 de fevereiro, 2014, em, http://www. cartacapital.com.br/tecnologia/na-internet-o-individuo-ficanu/

Nardi, H. C. \& Silva, R. N. (2009). Ética e subjetivação: as técnicas de si e os jogos de verdade contemporâneos. In S. Hunning \& N. Guareschi (Orgs.), Foucault e a psicologia (pp. 143-157). Porto Alegre: EDIPUCRS.

Recuero, R. \& Zago, G. (2012). A economia do Retweet: redes, difusão de informações e capital social no Twitter. Contracampo (UFF), 24(1), 19-43.

Rifkin, J. (2001). A Era do acesso. São Paulo: Makron Books. Vaz, P. (2010). Esperança e excesso. In A. Parente (Org.), Tramas da rede: novas dimensões filosóficas, estéticas e políticas da comunicação (pp. 189- 208). Porto Alegre: Sulina.

Weissberg, J. (2010). Paradoxos da teleinformática. In A. Parente (Org.), Tramas da rede: novas dimensões filosóficas, estéticas e políticas da comunicação (pp. 113-141). Porto Alegre: Sulina.

\section{Agradecimento}

À agência de fomento: Coordenação de Aperfeiçoamento de Pessoal de Nível Superior CAPES - bolsa de Demanda Social.

Submissão em: 06/05/2013

Revisão em: 01/04/2013

Aceite em: 07/07/2014

Camila Mozzini é doutoranda em Comunicação na Universidade do Estado do Rio de Janeiro (UERJ) com pesquisa financiada pela CAPES, doutoranda em Arte: Producción e Investigación na Universidad Politécnica de Valencia (UPV- Espanha), mestre em Psicologia Social e Institucional na Universidade Federal do Rio Grande do Sul (UFRGS) com pesquisa financiada pela Capes e graduada em Comunicação Social, habilitação Jornalismo, também pela UFRGS. Tem interesse no estudo das interfaces entre 
artes, tecnologias e suas implicações aos corpos. Endereço: Rua São Francisco Xavier, 524, $10^{\circ}$ andar, sala 10.121, bloco F, Pavilhão João Lyra Filho. Maracanã. Rio de Janeiro/RJ, Brasil. CEP 20550-900. E-mail: camila.mozzini@gmail.com
Inês Hennigen é psicóloga, doutora em Psicologia pela PUCRS, professora do Departamento de Psicologia Social e Institucional e do PPG em Psicologia Social e Institucional do Instituto de Psicologia da UFRGS. E-mail: ineshennigen@gmail.com 